\title{
Effective CCTV and the Challenge of Constructing Legitimate \\ Suspicion Using Remote Visual Images
}

\author{
Dr David Williams \\ School of Psychology \\ University of Hertfordshire
}

Comments and queries should be addressed to:

\author{
Dr David Williams \\ Senior Lecturer in Social Psychology \\ School of Psychology \\ University of Hertfordshire \\ College Lane \\ Hatfield \\ Herts. \\ England AL10 9AB \\ Tel 01707285250 e-mail D.A.Williams@herts.ac.uk
}

\section{Acknowledgements}

The author is grateful for the helpful comments of an anonymous reviewer and Ms. M. Ashram for gathering field data that is presented as part of this paper. 


\begin{abstract}
This paper compares the effectiveness of public CCTV systems according to meta-reviews, with what might be expected based upon theoretical predictions. The apparent gulf between practice and prediction is explored in the light of the challenges faced by CCTV operators in terms of effective target selection. In addition, counter-intuitive reactions by members of the public to situational symbols of crime deterrence may also undermine the efficacy of CCTV. Evidence is introduced and reviewed that suggests CCTV operators may employ implicit profiles to select targets. Essentially, young, scruffy males who appear to be loitering are disproportionately targeted compared with their base rate use of surveyed areas. However, the extent to which such a profile is diagnostic of criminal intent or behaviour is unclear. Such profiles may represent little more than 'pattern matching' within an impoverished visual medium. Finally, suggestions for future research and effective CCTV operator practice are offered in order to improve target selection.
\end{abstract}


Open street public CCTV systems are an ever-present feature of the modern urban landscape. Although current accurate figures are hard to find, it has been estimated that there are some 4.2 million cameras in the UK (Norris and McCahill, 2006; McCahill and Norris, 2003). This figure gives some flavour of just how far CCTV has come since the first large scale open public space system was deployed on the busy sea front of Bournemouth in 1985 (Norris, McCahill and Wood, 2004), to today where it is a ubiquitous feature of the modern urban and criminal justice landscape.

The growth of CCTV systems in the UK over the last two decades has been due in no small part to its perceived benefits. Public support for CCTV systems, as expressed in surveys, has been remarkably high (typically 8090\% 'happy' with CCTV; Spriggs, Gill, Argomaniz, and Bryan, 2005; Geake, 1993) although substantial methodological issues do cast a shadow over this apparent support (Ditton 2000; Ditton, 1998). Critical incidents such as the tragic case of the murdered toddler Jamie Bulger have done much to accelerate both public and Governmental support for CCTV systems, probably because such systems can come to represent a tangible response and symbol of action in the 'war on crime' (Norris and McCahill, 2006). 
Despite the apparent appeal of public CCTV, the efficiency of such systems in terms of crime deterrence and reduction has received somewhat mixed support. A major review undertaken by Welsh and Farrington (2002) examined 13 studies where levels of crime were compared between locations where CCTV had been introduced and a suitable control area. Outcome measures concerned a range of crimes, and the CCTV interventions were rated as having had one of four types of effect (measured on average 10.9 months after the CCTV systems were introduced). The results of this review are listed in table 1 below.

Table 1. A summary of the Welsh and Farrington (2002, table 3.1) CCTV review results.

\begin{tabular}{lll}
\hline Type of Effect & Definition of Effect & Studies
\end{tabular}

Desirable Effect Significant Decrease in Crime 5

Undesirable Effect Significant Increase in Crime 3

\begin{tabular}{lll}
\hline Null Effect & Evidence of No Effect on Crime
\end{tabular}

Uncertain Effect $\quad$ Unclear Evidence of Effect on Crime

1 
As can be seen in table 1, a decrease in crime is not found in the majority of studies that met the strict criteria for inclusion in the review, indeed, three studies actually found that crime had increased following the introduction of CCTV and a further four found no effect.

The somewhat mixed findings described above stand in contrast to the theoretical predictions in respect of CCTV. Researchers have outlined a number of ways in which CCTV might help to reduce crime (e.g., Armitage, 2002; Armitage, 1999; Welsh and Farrington, 2002). Such predictions may be divided using the traditional distinction between formal (official) and informal regulation. Informal factors include those aspects of the community and encounters with individuals within public spaces that might affect the behaviour of both potential victims and offenders alike. For example, if more people start to use a public space newly covered by CCTV then this may enhance natural surveillance between members of the public and so deter offenders (Jacobs, 1961). This may also improve social cohesion within public spaces and the perceived efficacy of its inhabitants to intervene when the need arises (Sampson, Raudenbush and Earls, 1997). Potential offenders may also be deterred as a result of the panopticon effect of CCTV 
(Norris, 2003; Reeve, 1998; Foucault, 1977; Bentham, 1787). This concerns the way in which CCTV observation represents asymmetrical surveillance such that one may be aware that one could be seen, yet not be in a position to verify this. One cannot watch the watcher and so continual and internalised self-discipline becomes an appropriate response on the part of potential offenders. For victims too, the presence of CCTV may represent a symbol of law and order that both encourages resistance when faced with offences in public, and greater precaution with possessions and behaviour. This is because CCTV may serve to remind people that crime is an everpresent problem and others with whom they share public spaces may not be trusted (Williams, 2007; Armitage, 2002).

Aside from informal factors that affect potential victims and offenders without the direct intervention of officials, there are also factors that directly involve officials or those with formal authority, such as when the police use recorded images to identify suspects in subsequent investigations. And again, the efficient deployment of police or other formal resources via CCTV coordinated operations might be expected to aid detection. Live monitoring of CCTV images may also mean that officials can intervene early in an escalation sequence to both avert more serious crimes and 
capture perpetrators who might otherwise be hard to detect after the event (Welsh and Farrington, 2002). In these formal matters, CCTV might act as the means via which a 'capable guardian' may respond to the 'motivated offender' (Felson, 2000; Clarke and Felson, 1993). Salient CCTV systems may be one situational aspect that the potential offender ought to take account of before choosing to commit crime (Clarke, 1995). An illustrated summary of the ways in which CCTV systems might deter or reduce crime is shown in figure 1 below.

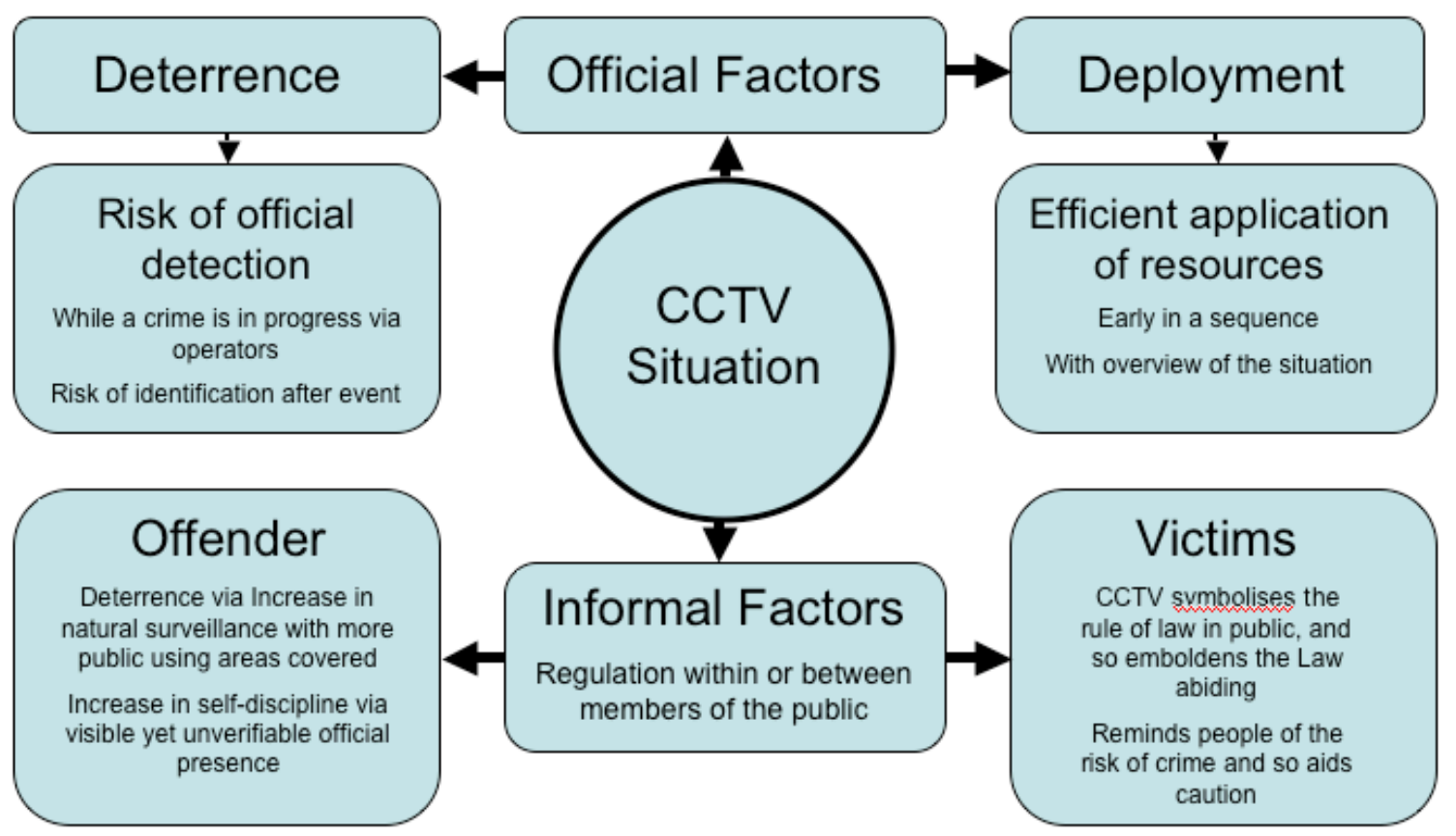

Figure 1. An illustrated model of how CCTV may affect crime.

Despite the intuitively appealing array of arguments that can be marshalled in defence of CCTV efficiency, it remains the case, as summarised in table 
1 , that such systems often fall short in this respect. On the informal side, in terms of both victims and potential offenders, research that describes (rather than predicts) people's attitudes towards CCTV helps explain some of the ‘inefficiencies’. For example, members of the public, as potential victims, may become habituated to the symbols of CCTV as a deterrence measure. Although Gill and Spriggs (2005) found a positive correlation between an awareness of cameras and their density, this correlation was not significant. Without being in special need of CCTV, people may simply not attend to these devices in a way that would affect their risk-taking behaviour (Ditton, 2000). What is more, such habituation also calls into question the 'panopticon' effect upon self-discipline. How can people respond appropriately to a disciplinary gaze if they are barely paying any attention to it, especially in the case of spontaneous crimes of the moment? Indeed, when noticed, such measures may even symbolise the danger that an area presents, and therefore undermine people's willingness to inhabit it and so offer informal regulation (Williams, 2007; Ditton, 2000; Jacobs, 1961). Finally, cameras may also present the illusory impression that any incident is already under observation and so reduce the likelihood that bystanders will intervene independently during a crisis (Latane and Darley, 1976). In essence, such as there is any effect, people seem as likely to 'ignore or 
withdraw' in response to CCTV, rather than become newly emboldened, self-disciplined, and informal regulators of public spaces.

\section{Limitations Affecting the CCTV Mediated Construction of Suspicion}

It is also possible that there may be some shortcomings evident in practice on the formal/official side too. As Norris and McCahill (2006) insightfully point out, there is often a gulf between abstract conceptions of how such CCTV systems may operate, and actual practice on the ground, which tends to be characterised by 'the selective concerns of the operators' (p19). Ultimately, it is not machinery that decides what constitutes an event or object worthy of monitoring in anticipation of potential further action; it is a human operator, acting within a workplace context and guided by preexisting stereotypes and conceptions of who and what is normal in a given location (Smith, 2004; Norris and Armstrong, 1999). So it seems reasonable to ask, how capable is the ordinary 'capable guardian’ that actually monitors CCTV screens?

Smith (2004 p391) points out that CCTV systems still largely rely on the "human element to both monitor and control cameras" and that despite 
some exceptions, this remains a neglected area of research. The CCTV screen observer faces a challenging task. The information upon which they must decide whether a target individual is or is not potentially deviant is relatively impoverished. Firstly, the surveillance is asymmetrical, in that the target cannot respond dynamically to a disciplinary gaze, via sound or visual modes, and this may distort the impression that targets give of themselves. For example, when a person knows for sure that they are being watched by an authority figure, they can modify their behaviour accordingly, and they can correct any impression that is open to misinterpretation, whether they are 'deviant' or not. This is part of everyday face work (Goffman, 1967) and helps make clear what a situation means for all those involved. Further, as no sound channel is generally present from target to monitor (although a trial using this is being run in Holland, Sunday Times November 26, 2006) innocent good-humoured communication may be confused with an aggressive interaction and visa versa. Finally, the specific nature of certain types of visual images may cause robust biases in person perception that result in the over-attribution of primed or expected traits within the target. For example, in a number of studies Daniel Lassiter and colleagues have shown that observers are more likely to attribute guilty intentions to a target within a video clip if the shot focuses on the person to the exclusion of the 
full situation they face (for a review see Lassiter, Geers, Munhall, Handley, and Beers, 2001). In essence, once selected, the very act of focussing in on an individual may render the viewer prone to a guilt attribution bias and therefore less likely to deselect the target from view (and so fail to attend appropriately to other participants in a scene).

In the light of the foregoing difficulties it is hardly surprising that CCTV operators face a daunting task when deciding who (or what) to select for legitimate monitoring; the technical mediation of the stimulus information itself may render the task much harder than it would be in 'real life'. Hopefully, CCTV operators can improve over time in terms of identifying what visual behaviour is and is not diagnostic of current or further serious criminal activity. As yet no research has compared target selection efficiency against operator experience; although research suggests that undoing the tendency to over-attribute negative dispositional inferences towards a target is particularly difficult when one expects to see immoral or antisocial behaviour (Gawronski, 2004; Reeder, Kumar, Hesson-McInnis, and Trafimow, 2002; for a review see: Skowronski, Carlston, 1989). The extent to which robust biases in person perception associated with remote visual images can be compensated for by direct experience of target selection 
outcomes, remains for the moment something of an open question, and one deserving of further attention in this applied context.

Of course, even where all modal channels are available, in real situations unmediated by visual images, such as where a police officer needs to separate the suspicious from the innocent citizen, it is hard to form an accurate judgement of deception (Vrij, 2004) or involvement in crime (Dunham, Alpert, Stronshine, and Bennett, 2005). Dunham et al., (2005) had observers follow 132 police officer duty tours in Georgia (USA) and found that an officer would 'form a suspicion' of a member of the public on just 1.32 occasions during any one shift $(\mathrm{M}=1.32, \mathrm{SD}=1.27)$. The reason for this suspicion was coded into four categories as follows; information about a suspect or situation (18.4\%), a person out of time and place (9.8\%), inappropriate overt behaviour (66\%), and distinctive appearance (5.7\%). On $59 \%$ of occasions the officer decided to stop the citizen based upon their suspicion. Once falling under suspicion, there was no significant correlation between the decision to stop and any broad demographic feature of the suspect such as age, gender, race, or class (although demographic factors are of course strong predictors of involvement in the CJS generally in the UK and USA, HO Statistical Bulletin 2005, Bureau of Justice Statistics Bulletin, 
2007). However, there was a significant positive correlation between the decision to make a stop, and the initial behaviour of the suspect $\left(\mathrm{r}=0.393^{* * *}\right)$. In other words, once a person had attracted the attention of an officer, the suspect's behaviour was the best predictor of whether the officer would go on to stop them. In an ongoing setting where a potential suspect has the capacity to see and respond to an authority figure, behaviour becomes an important predictor of the decision to stop, and the outcome of the stop. It is worth contrasting this situation with that of the potential suspect who may be selected for a CCTV surveillance pursuit. Here the target can give no dynamic response to the attention of a watcher, even if this could be noticed. The modestly intoxicated cannot appear to straighten themselves up and so look distinct from the dangerously drunk person, the temporarily uninhibited reveller cannot modify their demeanour to seem separate from those determined to take things to excess, and so forth. Even when suspect predictive behaviour is evident on the screen, the asocial nature of an asymmetrical gaze of which the target may have little if any awareness may undermine the discriminative value of such information. Remote visual surveillance may provide more opportunities for CCTV operators to observe and record examples of antisocial behaviour because this is unhindered by the physical presence of an authority figure. However, 
whether target selection based upon such 'uninhibited' sub-criminal behaviour will lead to an efficient level of positive identifications of subsequent serious deviant actions is as yet an unresolved matter and open to question based upon the current state of the literature. In sum, people's behaviour can be a poor indicator of legitimate suspicion in the presence of proxy symbols of authority, and this may be one additional reason why monitored CCTV systems are not as effective as might be expected.

It is interesting to note that in the Dunham et al., (2005) study outlined above, police officers had a basis to form suspicion a little over once every shift, perhaps far less than might be imagined. Similarly, Simon (2004) reports on the CCTV control room practices of a large educational institution and notes also that for most of the time, "(observers face)...an extremely long time...sitting staring at essentially nothing” (p388). Further, Norris and McCahill (2006) found that 'proactive' use of a CCTV system in a South London shopping mall was uncommon (i.e., there were 84 targeted surveillance pursuits over 120 hours of control room observation, just over 5 per shift). In addition, many of those targeted surveillance episodes that do take place seldom result in the need to deploy the police (45 times out of 900; Norris and Armstrong, 1999). In other words, for most of the time 
CCTV operators watch very ordinary and familiar scenes, for long periods, punctuated by relatively rare incidents judged worthy of pursuit, which most often end without the need for further action.

\section{CCTV and Implicit Suspect Profiles}

Unlike police officers on duty, operators have fewer means of avoiding boredom. They may be faced with little in the way of distinctive events or behaviour to view, and that which does occur may not be diagnostic of deviant behaviour (thus leading to futile pursuits of the innocuous). Under these circumstances perhaps the only criteria that an operator may use to determine who to watch when they actively choose to do so is going to be either the target's visual appearance or prior information and knowledge about a specific person.

Only a few studies have addressed the question of who is selected for observation within a CCTV control room; these include: Norris and McCahill (2006), Lomell (2004), Smith (2004), McCahill (2002), Wakefield (2000), and Norris and Armstrong (1999; 1997). The results of these studies 
generally show that it is 'the usual suspects'- those that fit certain demographic profiles, such as age, gender and race in a manner that fits with pre-existing stereotypes related to crime tend to be picked out. For example, Norris and Armstrong (1997) found that CCTV operators disproportionately targeted young blacks and males, while Norris and McCahill (2006), Lomell (2004), Smith (2004) and Wakefield (2000) found that the young and those that appeared to be 'flawed consumers' (scruffy or dressed to fit a youth subcultural group) were more likely to become a target than others. Such findings have obvious implications for the effective use of CCTV as well as unjust deviance amplification processes affecting certain groups and those on the economic margins of society (Norris and Armstrong, 1997; Cohen, 1972).

One difficulty with the foregoing studies concerns making accurate comparisons between who is targeted by CCTV operators against who was actually using the area at the time. That is to say the target demographic profile needs to be compared against who is actually using the area at the time in order to be sure that the apparent distortions in target selection are due to operator bias and not base rate effects associated with the type of people that choose to use the area at a given time (for similar observations in 
which suspect selection profiles are adjusted according to their base rate use of a location see, Parker, MacDonald, Alpert, Smith, and Piquero, 2004; Meehan and Ponder, 2002). In order to combat this problem, a researcher working with the author of this paper observed CCTV operator behaviour within a control room and compared target selection profiles with demographic information about who was actually using the area under surveillance at the time. Details of the control room will remain anonymous for the purposes of this paper, but it was situated in a major metropolitan conurbation in the South of England and funded under a Town Centre Management Scheme partnership (TCMs, involving the local borough, retailers, chamber of commerce, businesses, landowners, with the local police authority in overall control).

The control room was equipped with 12 monitor screens fed by 42 pan tilt and zoom (PTZ) cameras which were located in and around the central commercial area of the borough. The main screen image was recorded in 'real' time and was positioned in the centre, and images from other screens could be directed to this at the operators' discretion. Contact with private shop security staff, shop staff and the police could be made via phone, mobile phone and radio equipment at the console. A computer was also 
housed at the console, and this gave operators access to a local police computer database that held photos and a small amount of information about local 'known offenders'. There were 5 operators that worked in the control room in shifts.

For 5 days in one week between the hours of $9.00 \mathrm{am}$ to $5.00 \mathrm{pm}$ the researcher coded a range of details about the targets that were selected for observation, including how long they were pursued and the reason given or volunteered for the pursuit. In the week following this coding the researcher went to typical locations under surveillance by the system. The range of public street settings were selected to avoid any potential confounds and to be as representative of the type of scenes observed in the control room in the previous week as possible. The coder then recorded demographic information about who was using these areas until the $n$ of observations matched that for the total of the previous week. This information was then used in order to compare target profile information with the demographic profile of those that actually use the surveyed area. The descriptive results of this exercise appear in table 2 below.

Table 2. Counts for CCTV target and area use by demographic groups 


\begin{tabular}{lclc}
\hline Demographic & CCTV Targets $^{\mathbf{a}}$ & Area Users $^{\mathbf{b}}$ & Difference (a-b) \\
\hline Gender & & & \\
\hline Male n (\%) & $132(73.7)$ & $081(45)$ & 51 \\
\hline Female & $047(26.3)$ & $099(55)$ & -52 \\
\hline Age & & & \\
\hline $10-20$ & $042(23.5)$ & $016(08.9)$ & 26 \\
\hline $21-30$ & $081(45.3)$ & $047(26.1)$ & 34 \\
\hline $31-40$ & $028(15.6)$ & $039(21.7)$ & -11 \\
\hline $41-50$ & $015(08.4)$ & $042(23.3)$ & -27 \\
\hline $51-60+$ & $013(07.3)$ & $036(20.0)$ & -23 \\
\hline
\end{tabular}

Ethnicity

\begin{tabular}{lccc}
\hline White & $163(91.1)$ & $168(93.3)$ & -5 \\
\hline Black & $011(06.1)$ & $006(03.3)$ & 5 \\
\hline Asian & $004(02.2)$ & $004(02.2)$ & 0 \\
\hline Chinese & $001(00.6)$ & $002(01.1)$ & -1 \\
\hline Other & $000(00.0)$ & $000(00.0)$ & 0
\end{tabular}

Appearance

\begin{tabular}{lccc}
\hline Scruffy & $087(48.6)$ & $025(13.9)$ & 62 \\
\hline Sub-Cultural & $004(02.2)$ & $000(00.0)$ & 4
\end{tabular}




\begin{tabular}{llll}
\hline Casual & $077(43.0)$ & $132(73.3)$ & -55
\end{tabular}

\begin{tabular}{llll}
\hline Smart & $011(06.1)$ & $023(12.8)$ & -12
\end{tabular}

An analysis of data presented in table 2 show that cell frequencies for gender differed significantly $\left(X^{2}=30.7, \mathrm{df}=1, \mathrm{p}<0.001\right)$ as did age $\left(X^{2}=46.1, \mathrm{df}=4\right.$, $\mathrm{p}<0.001)$ and appearance $\left(X^{2}=57.0, \quad \mathrm{df}=3, \quad \mathrm{p}<0.001\right)$. However the frequencies for ethnicity did not differ significantly across observation locations $\left(X^{2}=1.88, \mathrm{df}=3, \mathrm{n} . \mathrm{s}\right)$. As can be seen from the table, after adjustment is made for who uses the area under surveillance, a target is more likely to be a young male of scruffy appearance. The most common reason given for the initial target being selected (by the CCTV operator) was 'loitering'. The typical duration for target pursuit was 91.07 seconds and interestingly there was a significant difference in pursuit duration between males $(M=100.83, S D=130.28)$ and females $(M=63.65, S D=83.33)$ with males being observed for significantly longer than females $(t[127.1]=2.36$, $\mathrm{p}<0.05)$.

The foregoing results are somewhat limited by the fact that coding was only undertaken between 9.00 am and 5pm on weekdays. It is possible, indeed likely, that the demographic profile of those using the areas in question 
would change markedly on (for example) a Saturday night, and it is not possible to say whether base rate adjusted target profiles would remain constant outside the hours that were tested here. However, the results covering the time period in question do support previous findings in that young males of 'scruffy' appearance are the most likely to be selected for pursuit. And what is important here is that this remains the case even after carefully controlling for the demographic profile of who is using the area at the time target selections are made. Of course, it is also not possible to say whether this means that operators depend entirely upon simple visual cues related to demographic and social-economic factors in order to select targets, because target behaviour is confounded with target type in this and (almost certainly) other studies. Moreover, data related to the outcome of a pursuit in comparison to those in a scene who are not selected for pursuit is not available. We simply cannot know whether those in the field that escape the attention of a CCTV operator are more or less likely to be involved in crime. To put it another way, until a yoked sample of 'older women of smart appearance' are approached and questioned by the police in the way a typical target might be at the end of a suspicious pursuit period, then it is not possible to say that the profile which is being used, confounded as it is by behaviour, is not a reasonable basis for selecting targets in these 
circumstances. It may yet prove diagnostic of criminal intent. That said, little in terms of the outcome of pursuits, which seldom require further action, or the overall efficacy of CCTV systems as described in the review above, would suggest that target selection has high discriminant validity, and therefore that either behaviour or basic demographic features are good predictors of criminal activity. In essence, operators do in practice appear to employ implicit suspect/target profiles, and these concern specific demographic groups displaying certain types of behaviour such as loitering. However, whether such profiles are themselves diagnostic of significant criminal behaviour, remains open to question.

\section{Conclusion: Improving Target Selection}

Current training for public space CCTV operators in the UK falls under the control of the Security Industry Authority (SIA), which oversees the awarding of licenses (Public Space Surveillance) to CCTV operators under statutory powers given in the Private Security Industries Act (2001) and regulation orders (2007: 810; Licenses). Training in CCTV practice leading to eligibility for a license to engage in PSS CCTV activity typically involves 30 hours teaching and assessment (e.g., those offered by EDEXCEL 2007 
and ASTS). As an example the ASTS course covers the following topics:

Role and responsibilities of CCTV operator and other CCTV staff Codes of practice, operational procedures and guidelines

CCTV equipment and its operation

Control room communications and access control

Legislation

Dealing with incidents

Surveillance techniques

Fire and emergency procedures

Health and safety

Notice that surveillance techniques, which are relevant here, are but one aspect of CCTV use. Under this same sub heading on the BTEC EDEXCELL (2007) program, tutors of PSS CCTV operators are invited to discuss with students (among other things) "how to recognize and interpret body language" and the "reasons and methods used when targeting" (p27). In respect of the former point, it is important that this refers to clear examples of actual criminal behaviour, as the research literature regarding the construction of suspicion based upon non-verbal gestures provides little 
hope that either expertise, training or any specific gestures viewed from close up, let alone at a distance and to the possible exclusion of context, is a reliable indicator of criminal intent and deception (Vrij, 2004; Mann, Vrij \& Bull, 2002,). What is more, certain non-verbal gesture styles are associated with specific demographic groups, and this fact alone may explain some biases in target selection (for example, innocent African Americans have been found to use more hand gestures and smiles during encounters with authority figures than Caucasians; Johnson, 2007). As to the other point concerning the reasons and methods used to select targets, the descriptive evidence reviewed above suggests that what is employed in practice may involve a simple pattern matching exercise in which targets that fit the existing offender population profile (i.e., young males; HO Statistical Bulletin, 2005) are over-selected. That is to say, despite training which cautions against selecting targets based upon demographic group membership, that is what happens in practice. The question remains as to whether such targeting is due to pre-existing negative social stereotypes; behaviour and gestures (non-criminal) that are associated with certain demographic groups; or may in fact be entirely legitimate based upon pursuit outcomes. The problem here is that as yet no evidence exists that has adequately addressed this question. This is because outcomes for non- 
selected targets have yet to be examined in a study that also allows for the base rate use of the surveyed area by certain demographic groups. However, this sort of comprehensive research is valuable for two reasons. 1., because it might help explain why CCTV systems are not as effective at crime detection and deterrence as might be expected and so feed into CCTV operator training, and 2., because the illegitimate over-selection of specific demographic groups may lead to unjust deviance amplification (Norris and Armstrong, 1997; Cohen, 1972). It may also be that when it comes to crime, the CCTV medium is sufficiently impoverished compared with real encounters with individuals on the street that whatever other uses it may be put to, when it comes to selecting potential offenders based upon legitimate suspicion, CCTV operators will always face challenges that can be seriously underestimated. There is a sense in which CCTV systems never fail; they continue to present and record images on screens using reliable and sophisticated technology. The real issue concerns whether such systems are always the most effective means of dealing with crime in public places, and if so, are the users of such systems able to take full advantage of this? 


\section{References}

Armitage, R. (2002) 'To CCTV or not to CCTV?' A review of current research into the effectiveness of CCTV systems' NACRO Community Safety Briefing, May

Armitage, A., Smyth, G. \& Pease, K (1999), 'Burnley CCTV evaluation.’ in

K. Painter \& N. Tilley (eds.) Surveillance of Public Space: CCTV, Street Lighting and Crime Prevention. Crime Prevention Studies Vol. 10, Monsey, New York

ASTS (Advanced Safety Training Services) Details of the CCTV activity eligibility course: Retrieved Nov $13^{\text {th }} 2007$ at:

http://www.ast-services.co.uk/cctv.html

Bentham, J. (1787) The panopticon, in M. Bozovic (ed.) The Panopticon Writings. London: Verso, (1995). 29-95

Bureau of Justice Statistics Bulletin (2007) Prisoners in 2005, U.S. Department of Justice, Office of Justice Programs, NJC215092 
Clarke, R. V. (1995) 'Situational crime prevention', in M. Tonry \& D. P. Farrington (eds.), Building a Safer Society: Strategic Approaches to Crime Prevention: Vol. 19. Crime and Justice: A Review of Research, 91-150. Chicago, Illinois: University of Chicago Press.

Clarke, R. V. \& Felson, M. (eds) (1993) Routine activity and rational choice, Advances in Criminological Theory, Vol. 5., New Brunswick NJ: Transaction Publishers

Cohen, S. (1972) Folk Devils and Moral Panics, London: MacGibb and Kee Ditton, J. (1998) 'Public support for town center CCTV schemes: myth or reality?' Ch. 12, in C. Norris, J. Morgan, and G. Armstrong (eds.) Surveillance, Closed Circuit Television and Social Control, Ashgate, Aldershot

Ditton, J. (2000)'Crime and the city: public attitudes towards open-street CCTV in Glasgow’ British Journal of Criminology, 40, 692-709 
Dunham, R. G., Alpert, G. P., Stronshine, M. S., \& Bennett, K. (2005) Transforming citizens into suspects: factors that influence the formation of police suspicion, Police Quarterly, 8, 366, DOI: $10.1177 / 1098611105274539$

EDEXCELL (2007) BTEC Short Courses: Edexcell Level 2 BTEC Award in CCTV Operations (Public Space Surveillance), Issue 2, UK Qualification and Curriculum Authority.

Felson, M. (2000) The routine activities approach as a general social theory, in S. S. Simpson (ed.), Of Crime and Criminality: The Use of Theory in Everyday Life. Thousand Oaks, CA, Pine Forge Press.

Foucault, M. (1977) Discipline and Punishment: The Birth of the Prison. London: Penguin Books

Gawronski, B. (2004) Theory-based bias correction in dispositional inference: The fundamental attribution error is dead, long live the correspondence bias, European Review of Social Psychology, 2004, 15, 183217 
Geake, E. (1993) 'The Electronic Arm of the Law', New Scientist, 8 May

Gill, M. \& Spriggs, A. (2005) 'Assessing the impact of CCTV', Home Office Research Study 292, Home Office Research, Development and Statistics Directorate

Goffman, E. (1967) Interaction Ritual, New York: Pantheon.

Home Office (2005) Statistical Bulletin: Criminal Statistics 2004 for England and Wales 19/05, RDS Office for Criminal Justice Reform (ed. M. Cornish)

Jacobs, J. (1961) The Death and Life of Great American Cities New York: Random House.

Johnson, R. R. (2007) Race and police reliance on suspicious non-verbal cues, Policing: an International Journal of Police Strategies \& Management, 30(2), 277-290 
Lassiter, D. G., Geers, A. J., Munhall, P. J., Handley, I. M., \& Beers, M. J. (2001) Videotaped confessions: is guilt in the eye of the camera? Advances in Experimental Social Psychology, 33, 189-254

Latane, B. \& Darley, J. M. (1976) 'Help in a crisis: bystander response to an emergency', in J. W. Thibaut \& J. T. Spence (eds.), Contemporary Topics in Social Psychology, 309-32. Morristown, NJ: General Learning Press.

Lomell, H. M. (2004), Targeting the unwanted: video surveillance and categorical exclusion in Oslo, Norway? Surveillance and Society, 2/2-3, $3472-61$

Mann, S., Vrij, A. \& Bull, R. (2002) Suspects, lies and video tape: an analysis of authentic high stakes liars, Law and Human Behaviour, 26, 365376

McCahill, M. \& Norris, C. (2003) 'Estimating the extent, sophistication and legality of CCTV in London', in M. Gill (ed.) CCTV, Perpetuity Press 
Meehan, A. J., \& Ponder, M. C. (2002) Race and place: the ecological of profiling African American motorists, Justice Quarterly, 19(3), 399-430

Norris, C. \& Armstrong, G. (1997) The Unforgiving Eye: CCTV Surveillance in Public Space, Hull: University of Hull

Norris, C. \& Armstrong, G. (1999) The Maximum Surveillance Society: The Rise of CCTV, Oxford: Berg.

Norris, C. (2003) 'From personal to digital: CCTV, the panopticon and the technological mediation of suspicion and social control', in D. Lyon (ed.) Surveillance and Social Sorting: Privacy Risk and Automated Discrimination, London: Routledge, pp. 249-81.

Norris, C., McCahill, M. \& Wood, D. (2004) 'Editorial: the growth of CCTV: a global perspective on the international diffusion of video surveillance in publicly accessible space', Surveillance and Society, 2(2/3) $110-135$ 
Norris, C. \& McCahill, M. (2006), CCTV: beyond penal modernism? The British Journal of Criminology, 46:97-118

Parker, K. F., MacDonald, J. M., Alpert, G. P., Smith, M. R., \& Piquero, A. R. (2004) A contextual study of racial profiling: assessing the theoretical rationale for the study of racial profiling at the local level, American Behavioral Scientist, 47, 943-62

Reeder, G. D., Kumar, S., Hesson-McInnis, M. S., \& Trafimow, D. (2002) Inferences about the morality of an aggressor: the role of perceived motive. Journal of Personality and Social Psychology, 83, 789-803

Reeve, A. (1998) 'The panopticisation of shopping: CCTV and leisure consumption', in C. Norris, J. Moran \& G. Armstrong (eds.) Surveillance, Closed Circuit Television and Social Control. Aldershot: Ashgate

Sampson, R. J., Raudenbush, S. W., \& Earls F. (1997) Neighborhoods and violent crime: a multilevel study of collective efficacy, Science, 277 August 
Skowronski, J. J., \& Carlston, D. E. (1989). Negativity and extremity biases in impression formation: A review of explanations. Psychological Bulletin, 105, 131-142

Smith, G. J. D. (2004) Behind the screens: examining constructions of deviance and informal practices among CCTV control room operators in the UK, Surveillance Society, 2(2/3) 376-395

Spriggs, A., Gill, M., Argomaniz, J. \& Bryan, J. (2005) 'Public attitudes towards CCTV: results from the pre-intervention public attitude survey carried out in areas implementing CCTV', Home Office Online Report 10/05, London: Home Office.

Sunday Times (Nov 26 ${ }^{\text {th }}$ 2006) Word on the street...they're listening. Retrieved 4 Nov 2007 at: http://www.timesonline.co.uk/tol/news/uk/article650166.ece

Vrij, A. (2004) Why do professionals fail to catch liars and how can they improve? Legal and Criminological Psychology, 9, 159-81 
Wakefield, A. (2000) Situational crime prevention in mass property, in A. von Hirsh, D. Garland, \& A. Wakefield (eds.), Ethical and Social Perspectives on Situational Crime Prevention, Oxford: Hart

Welsh, B. \& Farrington, D. P. (2002) 'Crime prevention effects of closed circuit television: a systematic review’, Home Office Research Study 252.

Home Office Research, Development and Statistics Directorate

Williams, D. A., \& Ahmed, J. (September, 2007) Person Perception In the Context of Public CCTV Systems: Trusting the 'Other' in the Modern Surveillance Society. Presentation given at the BPS Division of Social Psychology Conference Kent University, UK 